Portland State University

PDXScholar

\title{
La Casa de los Espiritus: Destruccion de Oposiciones Binarias
}

Teresa M. Sánchez Soultaire de Lamothe Portland State University

Follow this and additional works at: https://pdxscholar.library.pdx.edu/open_access_etds

Part of the Spanish Literature Commons Let us know how access to this document benefits you.

\section{Recommended Citation}

Sánchez Soultaire de Lamothe, Teresa M., "La Casa de los Espiritus: Destruccion de Oposiciones Binarias" (1993). Dissertations and Theses. Paper 4626.

https://doi.org/10.15760/etd.6510

This Thesis is brought to you for free and open access. It has been accepted for inclusion in Dissertations and Theses by an authorized administrator of PDXScholar. Please contact us if we can make this document more accessible: pdxscholar@pdx.edu. 
AN ABSTRACT OF the THESIS OF Teresa Sánchez Soultaire de Lamothe for the Master of Arts in Foreign Language and Literature: Spanish presented May 5, 1993.

Title: La casa de los espíritus:

Destrucción de oposiciones binarias

APPROVED BY THE MEMBERS OF THE THESIS COMMITTEE:

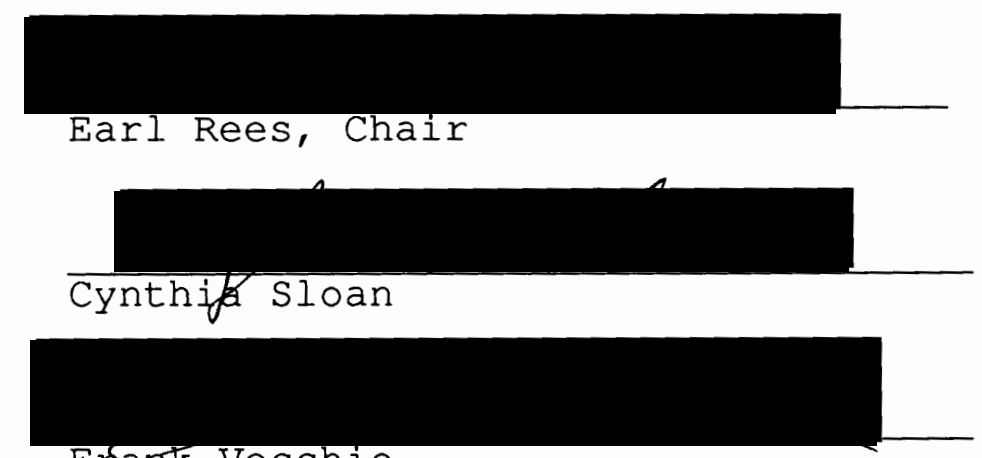

Frank Vecchio

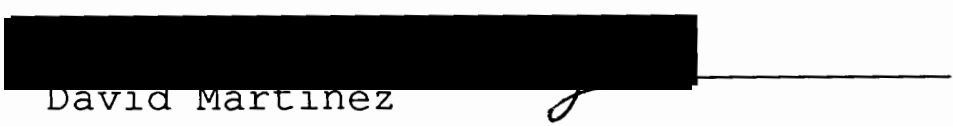

En las páginas de esta tesis se encuentra un análisis deconstructivo de las técnicas narrativas y el contenido temático-ideológico de la primera novela de la escritora chilena Isabel Aliende. Mediante el mismo, se ha tratado de descubrir en la casa de los espíritus una actitud de rebeldía en contra de las formas de poder que se manifiesta en diversos niveles de la vida social, y que, según el crítico 
uruguayo Angel Rama, caracteriza la obra de algunos escritores hipanoamericanos contemporáneos.

Diferentes técnicas narrativas, quedan analizadas, dando mayor énfasis al uso del realismo mágico, el cual crea una oposicion en la estructura del texto, que va a continuar en su contenido. Esta oposición, al igual que las expuestas por el contenido temático-ideológico, queda disipada luego de ser estudiada más a fondo.

Además, se enumeraron y analizaron las distintas visiones de instituciones sociales, como la Iglesia, la familia y el gobierno, encontradas en el texto, que logran dar al lector un resumen del contenido ideológico que Allende trata de exponer en su obra.

Dos perspectivas de la Iglesia, por ejemplo, son expuestas. La Iglesia defensora de ideologías derechistas y la Iglesia que aboga por ideales izquierdistas. Ambas quedan convertidas en una misma; una institución defensora de ideologías basadas en la oposición binaria inicial rico/pobre establecida por el poder económico. Ante la incapacidad de la Iglesia como institución para resolverse hacia una forma de vida particular, surgen otras alternativas, otras perspectivas de vida. Estas tienen el efecto de mantener a las masas en un punto medio donde sse disminuye la fuerza de cualquier oposición verdadera al poder económico. De igual manera, quedan deconstruidas otras instituciones sociales en la novela. 
En el estudio se constata cómo, tanto las oposiciones entre técnicas narrativas, como las oposiciones entre ideologías quedan destruidas en esta obra. Con la destrucción de oposiciones binarias, la autora denuncia las injusticias de un sistema social, dominado por el poder económico norteamericano que ha golpeado su patria cruelmente. 
LA CASA DE LOS ESPIRITUS:

DESTRUCCION DE OPOSICIONES BINARIAS

by

TERESA M. SANCHEZ SOULTAIRE

de LAMOTHE

\begin{abstract}
A thesis submitted in partial fulfillment of the requirements for the degree of
\end{abstract}

\author{
MASTER OF ARTS \\ in \\ FOREIGN LANGUAGE AND LITERATURE: \\ SPANISH
}

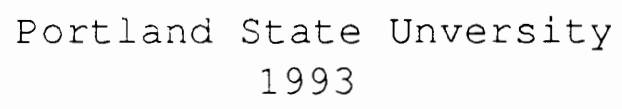


TO THE OFFICE OF GRADUATE STUDIES:

The members of the Committee aprove the thesis of Teresa Sánchez Soultaire de Lamothe presented May 5, 1993.
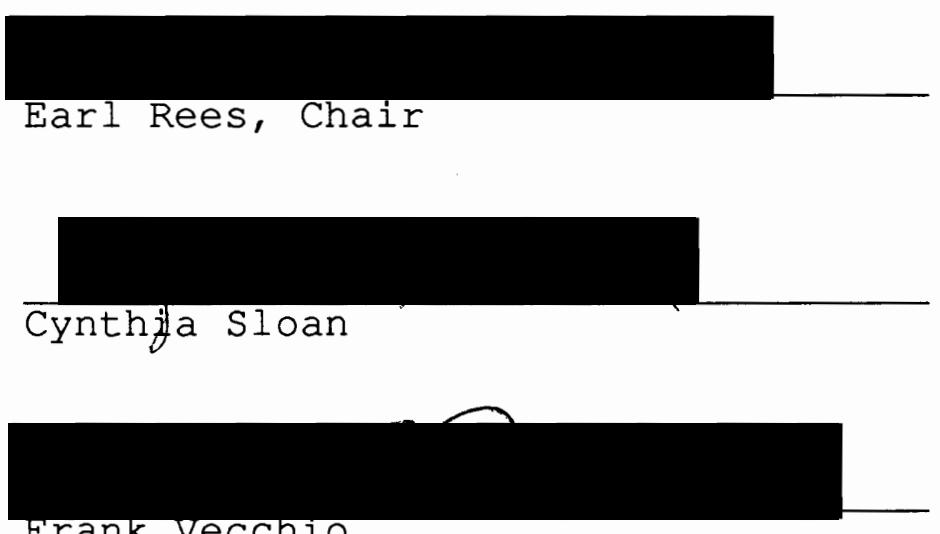

Frank vecchio

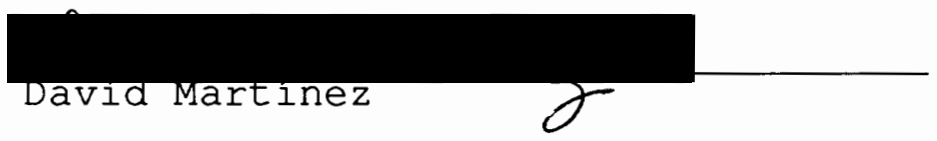

APPROVED :

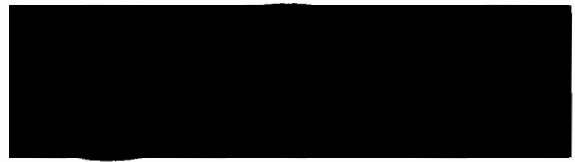

Linda B. Parshall, Chair, Department of Foreign Languages and Literatures

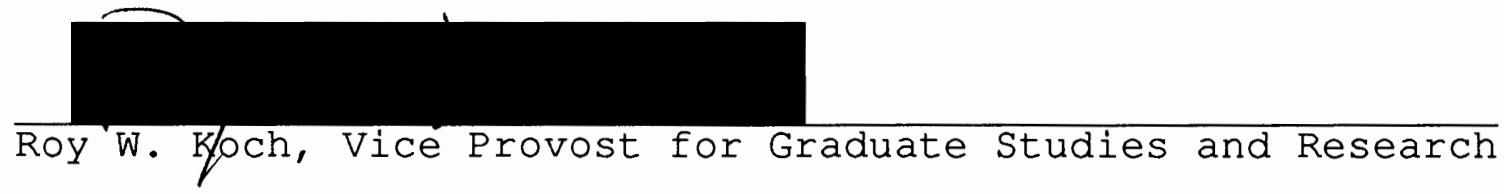


TABLA DE CONTENIDOS

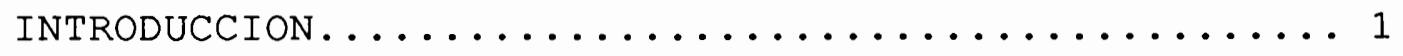

MODOS DE ORGANIZACION Y TECNICAS NARRATIVAS........ 3

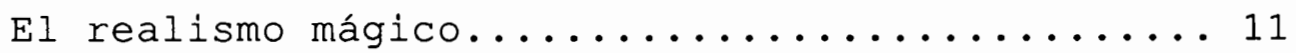

ANALISIS A NIVEL TEMATICO-IDEOLOGICO............ 21

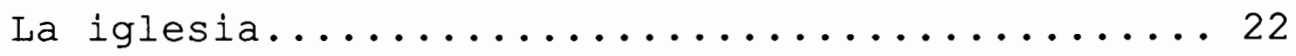

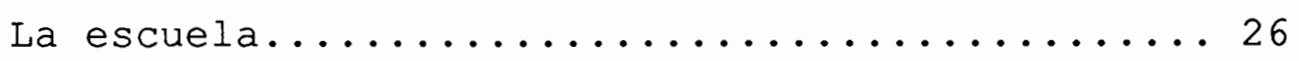

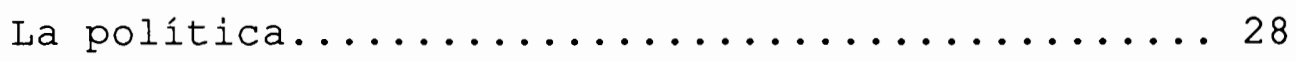

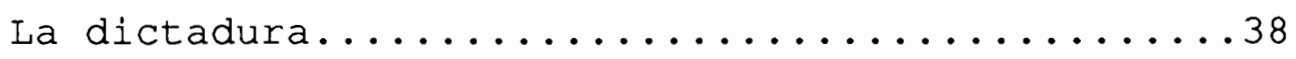

Los militares....................... 40

La familia y la sociedad.................47

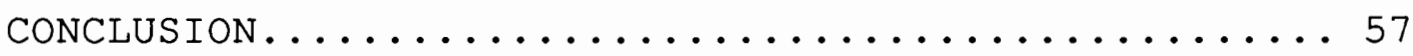

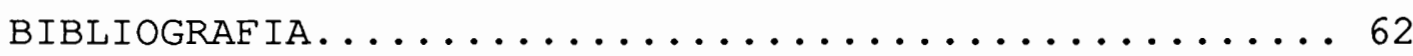




\section{INTRODUCCION}

"When I say I don't have an intention, it's because I don't want to clarify anything, ${ }^{1}$ con estas palabras la novelista chilena, Isabel Allende, reafirma 10 que se hace muy patente a través de su novela: La casa de los espiritus, definitivamente, no es una clarificación de sucesos historicos.

En 1982, Isabel Allende publica La casa de los espiritus, una saga familiar basada en los acontecimientos histórico-políticos de Chile. Aunque la escritora se basa en eventos "reales", La casa de los espiritus está lejos de formar parte del subgénero literario de la novela testimonial. En su primera novela, Allende enreda al lector en una destrucción constante de oposiciones binarias, ${ }^{2}$ que junto a las técnicas narrativas, hace que esta obra se sume a otras pertenecientes a la Nueva Narrativa Hispanoamericana. Desde los años 60 escritores como el peruano Mario Vargas Llosa, el colombiano Gabriel García Márquez, el mexicano Carlos Fuentes, el argentino Julio Cortázar y otros a los que ahora sumamos a Isabel Allende, han logrado captar la

1 Isabel Allende, "Interview with Isabel Allende," Confluencia 6-1 (1990): 93 .

2 Con oposiciones binarias me refiero a la relación de dos elementos opuestos en la obra literaria, sujeto de análisis en la crítica estructuralista. 
atención del mundo con el uso de nuevas técnicas narrativas que ayudan al escritor a reflejar las distintas realidades de la existencia latinoamericana.

Según el crítico uruguayo, Angel Rama, la obra de estos escritores, marcados en mayor o menor grado, por la experiencia del 68-"año de rabia $y$ de esperanzas pero también de enormes frustraciones" (46)-, se caracteriza por una actitud reprobatoria y rebelde contra todas las formas del poder que se manifiestan en diversos niveles de la vida social y que afectan "tanto las relaciones sexuales como las estructuras lingüísticas, la organización aparentemente racional del discurso como las formas legales de la explotación económica, la estructura familiar como el sistema de clases. ${ }^{3}$

En este estudio, se hará un análisis las técnicas narrativas y del contenido ideológico presentado en la casa de los espiritus con el fin de descubrir la "actitud reprobatoria y rebelde" que supuestamente caracteriza la obra de los escritores hispanoamericanos contemporáneos.

3 Juan Manuel Marcos, "Multiciplidad, dialéctica y reconciliación del discurso en La casa de los espíritus," 61-70 En Coddou, Marcelo (ed.) Los libros tienen sus propios espíritus. Veracruz: U. Veracruzana, 1987. 
MODOS DE ORGANIZACION Y TECNICAS NARRATIVAS

La novela está dividida en catorce capítulos con subdivisiones en cada uno de éstos, en este sentido la obra puede parecer muy tradicional. Sin embargo, existe una línea imaginaria que divide el texto en dos partes y borra la tradicional división entre capítulos.

La primera parte de la casa de los espíritus, que siguiendo la línea divisoria imaginaria, se extendería hasta el capítulo X, "La época del estropicio", es una sucesión de acontecimientos que resume la manera en que comienzan a acumularse las diversas ideologías que representan la niñez y temprana adolescencia de la escritora y de la historia del país, el período antes del golpe militar. Esta parte consta de una saga familiar en la que Alba y Esteban Trueba exponen para sí mismos y para el lector cómo comienzan a acumularse y a entrelazarse los conflictos que finalmente llevan a la familia y al país a Ia violencia. Esta parte está mayormente basada en los cuadernos de anotar la vida de la abuela de la narradora, Clara, y utiliza una técnica narrativa mágicorealista.

El resto de los capítulos son una descripción casi testimonial de los sucesos acaecidos en Chile durante los años 60 y 70, cuando la narradora y el país despiertan a una 
dictadura militar. El despertar físico de la narradora, coincide con el despertar ideológico, al cual ella llega por el amor y el pueblo llega por la violencia.

Una técnica que causa confusión en el lector y que aleja esta novela de los textos tradicionales es el punto de vista narrativo. En su mayor parte, el relato nos llega a través de un narrador en tercera persona, quien además es actante o personaje en la historia. En ocasiones, la narradora/ actante, Alba, interviene directamente en el hilo narrativo, convirtiéndose también en un narrador en primera persona. Así se ve cómo una misma persona se convierte a la vez en narradora omnisciente, en narradora en primera persona y personaje de su historia. Además de Alba, otro personaje, Esteban Trueba, también interviene en la narración en primera persona. De esta manera llega al lector una recolección de los sentimientos de "euforia y desilusión, de liberación y disipación, de carnaval y catástrofe"4 que el país acumula durante 50 años.

El patrón de intervenciones de la narradora en primera persona, que se establece desde la primera página, solamente lo encontramos en la primera parte del libro y en el epílogo. Esto se debe a que es sólo en la primera parte que Alba se convierte en:

4 Terry Eagleton, en su libro Literary Theory: An Introduction (Minneapolis: U. of Minnesota, 1983) 142, utiliza este término paradescribir el origen de la teoría crítica pos-estructuralista. Aquí se ha adoptado para describir la escritura de Allende. 
una editora que reconstruye una historia de otras escrituras: de las cartas de su madre, de lo registrado en los libros de administración del fundo Las Tres Marías y, sobre todo, de los cuadernos de anotar la vida. . . 5

El epílogo, es una especie de fluir de conciencia, donde la narradora se explica, y explica al lector al dejarlo escrito, cómo ha llegado a recolectar y a escribir los acontecimientos que su familia y ella han vivido.

Además de editora, Alba es crítica de estos textos anteriores. La narradora expone comentarios sobre ecrituras anteriores. Todo lo anterior tiene el efecto ilusorio de inclusive yuxtaponer el relato de Alba, con el contenido de los cuadernos de anotar la vida de su abuela Clara.

En algunos momentos tengo la sensación de que esto ya lo he vivido y que he escrito estas mismas palabras, pero comprendo que no soy yo, sino otra mujer que anotó en sus cuadernos para que yo me sirviera de ellos. ${ }^{6}$ (410)

Otro indicio de la yuxtaposición de relatos lo encontramos en sus contenidos. El hecho de que Alba comience su narración con la llegada de Barrabás a la familia del Valle nos indica que la narradora se está proyectando en este personajes de la primera historia. Su proyección se debe a la similitud de las condiciones en que Barrabás llega a la familia y en las que Alba se encuentra en la perrera. Aunque

5 Mario A. Rojas, "La casa de los espiritus de Isabel Allende: Un caleidoscopio de espejos desordenados," Revista iberoamericana 51132 (1985): 924 .

6 Isabel Allende, La casa de los espíritus (Barcelona: Rosés, 1982): 410. En adelante aparecerá el número de página incluido en el texto. 
los siguientes pasajes están separados por más de trescientas páginas, uno pudiera ser la continuación del otro: Barrabás "venía en una jaula indigna, cubierto de sus propios excrementos y orines, con una mirada extraviada de preso miserable e indefenso . . ." (9), y en la perrera Alba "dejó de comer, de rascarse, de olerse, de quejarse, y llegó a vencer, uno por uno, sus innumerables dolores. . ." (392)

A pesar de todo esto, el lector no puede asegurar que la narración llegue a través de solamente dos voces, las de Alba y Esteban. Los textos de las escrituras originales nunca los vemos, sólo nos llega la versión finalizada de Alba. Alba no transcribe la información tal y como la recibe, sino que se "sirve" de ésta para reconstruir su historia.

Ya entonces tenía el hábito de escribir las cosas importantes y más tarde, cuando se quedó muda, escribía también las trivialidades, sin sospechar que cincuenta años después, sus cuadernos me servirian para rescatar la memoria del pasado y para sobrevivir a mi propio espanto. (9)

Por otro lado, las voces de los espíritus se hacen escuchar constantemente. Inclusive, como antes se mencionó, la voz de Esteban Trueba interviene directamente en la narración. Esta situación crea una confusión tanto en el lector, como en la misma narradora, que intenta comprender si en realidad está frente a una sola voz con un solo punto de vista; o si por el contrario hay varias voces, presentando puntos de vista variados. Esta confusión no permite decidir si existe o no objetividad narrativa en el texto. 
The difficulty of such a structure occurs in the fact that a variety of voices come together in one history-Clara's notes retold through Alba's "objective" third-person narrative, Esteban's first-person memoirs, and Alba's first-person epilogue. Each voice points the reader in a different direction. ${ }^{7}$

La yuxtaposición ilusoria de relatos también tiene el efecto de distorcionar el tiempo en la mente de la narradora. A través de su voz escrita, Alba da nueva vida a los espiritus de su pasado. Su historia pasada se convierte en su presente, sus pasiones pasadas cobran nuevos significados que se manifiestan a través de otros personajes en el momento en que escribe sobre éstos. Esto no quiere decir que su versión actual de su pasado sea ficticia en su totalidad, sino que simplemtente es un nuevo punto de vista de la misma. La nueva interpretación del pasado puede ser tan válida como las anteriores o las de otras personas que también quedan expuestas en el texto. A pesar de esta multiplicidad de perspectivas, no se puede aseverar que La casa de los espíritus sea un texto pluralista.

- . in the traditional sense it is not. Traditionally, pluralism means that by positing a variety of ideas, by looking at an issue from a number of different perspectives, we will achieve a complete picture of "the truth." But no such truth, no logos appears in Allende's novel. Just at the moment we would expect a conclusion, during the last sentences of Alba's epilogue, Allende deprives us of just such an easy satisfaction . . ${ }^{8}$

7 E. Thomson Shields, Jr., "Ink, Blood, and Kisses: La casa de los espiritus and the Myth of Disunity," Hispanefilia 99 (1990): 82.

8 E. Thomson Shields, 84. 
En realidad, nadie puede definir cuál versión contiene más validez, ya que existen muchos puntos de vista y todos son válidos ya que son perspectivas de distintas personas, en distintos momentos de sus vidas. Así se entremezclan las realidades del pasado, con las del presente, las realidades de unos (que son las ficciones de otros) y de otros,. confundiéndose al punto que ya no se pueden separar los tiempos, ni las realidades.

La retrospeccion o "flashbacks" y la prolepsis son otras técnicas que utiliza Allende para crear esta confusión temporal. Por ejemplo, la mayoría de la acción del primer capitulo transcurre durante un día, el Jueves Santo en que Barrabás, junto al cadáver del tío Marcos llega a la familia del Valle. Sin embargo, la narradora nos lleva en este capítulo a recordar un pasado anterior al expuesto en las primeras páginas. Así nos enteramos de la vida del tío Marcos, para luego volver a la acción del día Jueves Santo.

Por otro lado, dentro de la narración sobre el tío Marcos se incluyen adelantos de acontecimientos que ocurrirán más tarde. Por ejemplo, cuando Marcos anuncia que se va a elevar en la máquina de "aspecto de pato herido"(20), la narradora nos adelanta que:

cuarenta años después, su sobrino nieto Nicolás, a quien Marcos no llegó a conocer, desenterro la iniciativa de volar que siempre estuvo presente en los hombres de su estirpe."(20)

Adelanta además que:

ninguna concentración política pudo reunir a 
tanta gente [como reúne Marcos con su iniciativa de volar] hasta medio siglo después, cuando el primer candidato marxista aspiraba, por medios democráticos, a ocupar el sillón de los presidentes. (20)

De esta manera, la novelista no sólo logra confundir los tiempos y los espacios, sino que advierte al lector que una saga familiar no es el único propósito de su escrito. El lector debe estar alerta, ya que entre la líneas de la historia familiar se encuentra otra historia.

La segunda parte del primer capítulo nos lleva a un tiempo y un espacio completamente distinto. Inclusive el narrador ha cambiado. Esteban Trueba nos narra sus experiencias en la mina cuando tenía veinticinco años. Así se yuxtaponen además los relatos, los tiempos y los espacios de Alba, la familia del Valle y Esteban Trueba.

El segundo capítulo nos traslada al fundo Las Tres Marías, donde transcurren alrededor de nueve años en la vida de Trueba, hasta el momento en que decide casarse con Clara. A través de este capítulo se utiliza un Leitmotiv, "Pearo García, el viejo, lo vio salir silbando camino al establo y movió la cabeza inquieto," que nos apunta hacia un giro importante en la novela. El Leitmotiv nos premoniza el abuso de poder, la violación de derechos humanos y las venganzas que más tarde se desarrolian en la historia del país. Pedro García, el viejo, al igual que Clara puede predecir la catástrofe debido a su experiencia y sabiduría. 
El capítulo tres, nos lleva nuevamente atrás en el tiempo para presentarnos la vida de Clara durante sus nueve años de mudez. En la segunda parte del capítulo tres se unen las vidas de Esteban y Clara. De aquí en adelante la narración sigue una cronología mayormente tradicional. El orden se sigue de acuerdo a acontecimientos importantes en la familia. Con la relación de "Los amantes", Blanca y Pedro Tercero García, comienza a perfilarse la diferencia de clases sociales. "La venganza" añade un giro violento a la historia de la familia. En este capítulo es que se presenta a Esteban García, nieto bastardo de Trueba, como traidor de su propia sangre. "Los hermanos", Jaime y Nicolás, buscan alternativas distintas a la vida en la gran casa de la esquina debido a las oposiciones entre las formas de vida de sus padres. "El conde" es quien echa la leña al fuego para que comiencen a desarrollarse los eventos violentos. "La niña Alba" nace en medio de este mundo desordenado, pero es protegida de otra realidad que la inventada para ella. "La época del estropicio" termina con el "orden" que con la evasión de la realidad establece Clara, se fragmenta la familia. Los capitulos restantes describen la situación de Alba después de enfrentar otras realidades que no conocía hasta ese momento. 
EL REALISMO MAGICO

otra técnica que merece especial atención, es el uso de la narración mágicorealista. ${ }^{9}$ Para explicar la manera en que Allende utiliza esta modalidad del discurso narrativo, que constituye el realismo mágico, volveré a la línea imaginaria que divide aparentemente el texto en dos partes opuestas.

Al utilizar estilos narrativos diferentes, la narradora traza una línea divisoria entre dos partes de la novela, representando de esta manera los dos períodos en que divide su vida y la del país. Esta oposición, como veremos más adelante, se disipa dependiendo de la perspectiva desde que se contemple, comenzando con la técnica un patrón que también seguirá con el contenido temático-ideológico del texto.

Como se mencionó anteriormente, en la primera parte de la novela la narradora, Alba, utiliza la técnica narrativa del realismo mágico. Esto es, Alba presenta una mezcla de realidad e irrealidad, un mundo mágico que a la vez es real.

En la novela vemos dos mundos que pudieran parecer opuestos. El mundo mágico de las primeras páginas, que ha

9 Según el crítico Angel Flores, el realismo mágico es una mezcla de realidad y fantasía [irrealidad], una transformación de lo común en lo sobrenatural e irreal y viceversa. (Véase Angel Flores, Magic Realism in Spanish American Literature) Otros escritores como el cubano Alejo Carpentier han llamado la técnica lo real maravilloso. Carpentier considera que lo maravilioso presupone un elemento de fe por parte del autor o por parte del público. También se ha definido el término como una realidad étnica, una unión o convivencia de realidades conceptuales y circunstanciales en un mundo en el que no se niega la posibilidad de realidades basadas en la fe, tal como la realidad de mundos étnicos. (Véase Suárez-Murias Margarite) 
sido comparado por muchos críticos con el mundo inventado por el escritor colombiano Gabriel García Márquez, ${ }^{10}$ parece tener fin en la segunda parte del libro, pero como veremos esta oposición desaparece. Ambos mundos son mágicos y a la vez reales.

Los personajes de La casa de los espiritus parecen utilizar lo mágico como instrumento para evadir otras realidades. De hecho la escritora ha dicho que:

cuando vivimos en contacto permanente con todas las formas de violencia y de miseria, hay que buscar explicaciones y encontrar esperanzas en lo sobrenatural. La realidad es tan brutal que necesitamos el refugio de un mundo mágico o espiritual.11

Tanto Clara, como otros personajes en la novela, incluyendo a Esteban Trueba utilizan mundos inventados para evadir realidades que no quieren vivir.

Clara pasó la infancia y entró en la juventud dentro de las paredes de su casa, en un mundo de historias asombrosas, de silencios tranquilos,

10 Muchos críticos han señalado el paralelismo entre el mundo mágico de La casa de los espiritus y el Macondo del colombiano Gabriel García Márquez. En realidad la primera impresión del lector al pasar las primeras páginas de la novela de Allende es la de estar leyendo una copia de cien años de soledad. De hecho, la crítica ha alegado que ésta es una novela, "which may begin as an attempt to rewrite one Hundred Years of Solitude, but which discovers itself as a unique statement." (Véase Robert Antoni) Vistas desde el punto de vista del crítico francés Roland Barthes, as alegaciones anteriores pierden validez. Barthes piensa que "all literary texts are woven out of other literary texts, not in the conventional sense that they bear the traces of 'influence' but in the more radical sense that every word, phrase or segment is a reworking of other writings which precede or surround the individual work. There is no such thing as literary 'originality', no such thing as the 'first' literary work: all literature is 'intertextual'.

(Véase Terry Eagleton, 138)

11 Gloria Bautista, "El realismo mágico en La casa de los espiritus," Discurso Literario 6-2 (1990): 308. 
donde el tiempo no se marcaba con relojes ni calendarios y donde los objetos tenían vida propia, los aparecidos se sentaban en la mesa $y$ hablaban con los humanos, el pasado y el futuro eran parte de la misma cosa y la realidad del presente era un caleidoscopio de espejos desordenados donde todo podía ocurrir. (84)

Luego de salir de la casa de sus padres, Clara traslada su mundo en la gran casa de la esquina, donde también logra evadir la realidad de un matrimonio sin amor.

Sin embargo, desde otra perspectiva se puede interpretar el mundo mágico como una expresión de las distintas formas "de la cultura marginada que se han ido desarrollando en el país[Chile]: los grupos que portan una visión del mundo y una producción de sentidos simbólicos alternativa a la ideología oficial."12

Luego, ¿en qué verdaderamente consiste lo mágico? ¿Consiste en una manera de evadir la realidad o una técnica de los personajes de Allende para denunciarla simbólicamente? En ambas perspectivas yacen lo real y lo imaginariosimbólico, por lo que la oposición entre ambas pierde sentido. Lo mágico ayuda a los personajes a evadir realidades desagradables y dolorosas. A la misma vez, la acción mágica se convierte en un acto simbólico de denuncia. Por ejemplo, el hecho de que clara decida "que no vale la pena hablar" por nueve años es un hecho "maravilloso". Clara trata de evadir la realidad de la que queda convencida después de la muerte

12 Juan Armando Epple, "El estado actual de los estudios literarios en Chile: Acercamiento preliminar," Hispamérica 56-57 (1990): 42. (En adelante se indicará el número de página en el texto) 
de su hermana Rosa; la muerte de su hermana ha sido culpa de su discurso hablado. Hay que recordar que Clara predice la muerte de Rosa y "tenía la terrible duda de que su hermana había muerto porque ella lo había dicho." (43) Para evadir la realidad dolorosa de predecir otros desastres, Clara elige el silencio. Sin embargo, su silencio dice más que mil palabras. La mudez de Clara se convierte en su testimonio, ya que el resultado de su mudez son los cuadernos de anotar la vida. Mediante éstos se va enterar el mundo de las injusticias sociales de su época.

La oposición realidad/irrealidad se disipa también debido a que los elementos mágicos del universo inventado para y por Clara, pueden parecer comunes para personas, que con mundos alternativos tratan de obtener una comprensión global de la sociedad, "de una sociedad cuyos fundamentos tradicionales han sido profundamente alterados." (Epple, 43)

Así es que las abilidades adivinatorias de Clara: su facilidad para predecir los terremotos, anunciar muertes, y sobretodo para interpretar sueños, son elementos que forman parte de la vida cotidiana en las cultura latinoamericana que trata de adivinar el sentido de su existencia. En el mundo de las primeras páginas se nos presenta también "la mesa de las tres patas". En ésta Clara se comunica con los espíritus del "Más Allá". En la primera parte de la novela se presenta este hecho como algo casi humorístico que sublima una realidad de la cultura en que se desarrollan los personajes de La casa. 
Sin embargo, en la segunda parte de la novela son las ánimas, junto a la última de la hermanas Mora, quienes entran en la biblioteca de Esteban Trueba para "anunciarle desgracias" (345) .

-No tengo la menor duda, Esteban -concluyo-. se avecinan tiempos atroces. Habrá tantos muertos que no se podrán contar. Usted estará en el bando de los ganadores, pero el triunfo no le traerá más que sufrimientos y soledad. (346

También el realismo mágico de las primeras páginas de La casa de los espiritus, a veces parece tener más realidad que irrealidad. El hecho de que el realismo mágico de Allende contenga una realidad casi morbosa advierte al lector que en el texto se van a presentar terribles realidades que no pueden łesconderse bajo 10 mágico. Inclusive cuando se nos presentan hechos irreales, como la cabellera verde de Rosa, se intenta buscar explicación al hecho sobrenatural, no ocurre así en otras novelas mágicorealistas. La familia del Valle trata de ocultar la belleza irreal de su hija pero ". . pronto se corrió la voz de que les había nacido un ángel."(12) La misma Clara la compara con un habitante del agua y piensa que "si hubiera tenido una cola escamada habría sido claramente una sirena."(12)

Las "realidades" descritas en la segunda parte del libro son casi idénticas a las que Clara veía como irrealidades, las que el padre Restrepo describiera en sus sermones para sembrar el terror e Dios. El padre Restrepo solía: 
describir los tormentos de los pecadores en el infierno, las carnes desgarradas por ingeniosas máquinas de tortura, los fuegos eternos, los garfios que traspasaban los miembros viriles, los asquerosos reptiles que se introducían por los orificios femeninos y otros múltiples suplicios . . (11)

Así es que Alba, que antes estuvo envuelta en el mágico mundo de la casa de la esquina, llega a conocer otras realidades que quedan grabadas dentro de su ser.

Alba es destinada a salir de la casona para relacionarse activamente con los grupos politicos de avanzada; primero lo hace tímidamente, más bien por amor a un dirigente estudiantil pero poco a poco se va identificando con las necesidades de los oprimidos y perseguidos políticos. Sus actividades clandestinas después del golpe militar la convierten en víctima de la tortura en un campo de concentración. Esta experiencia terrible, sin embargo, le abre las puertas a otro mundo...13

Este nuevo mundo también es un "caleidoscopio de espejos desordenados donde todo podía ocurrir."(84) • En este momento conoce un mundo donde existen el odio y la venganza, donde el poder económico crea la fantasía de una pacífica primavera, cuando en realidad el país está en guerra. En este mundo de locura, los militares "de una plumada cambiaron la historia universal, borrando los episodios, las ideologías y los personajes que el régimen desaprobaba." (362)

Para Alba, que vive dividida entre distintas realidades, el mundo se convierte en uno muy confuso, por eso decide escribir, para poner sus pensamientos en orden.

13 Mario A. Rojas, "Un caleidoscopio de espejos desordenados.," Revista Iberoamericana 132-133 (1985): 922 . 
Hasta los dieciocho años, Alba vivió enajenada de otra realidad que no fuera la inventada para ella por sus abuelos. Quizás este es uno de los demonios que Alba quiere exorcisar al escribir estas páginas, pues sinte nesecidad de denunciar unas realidades que lleva en su interior, pero en cierto modo quisiera evadir esta responsabilidad elevándose a un mundo mágico. Para Alba es difícil denunciar un mundo en el que ella vivio, del que ella formó parte $y$ en el que ve también lados buenos. Esto queda representado en la novela en la relación de Alba con su abuelo, Esteban Trueba. Alba está conciente de la maldad de su abuelo, pero también ha conocido sus mimos, su amor $y$, por consiguiente, no lo puede condenar. otras personas no ven a Trueba desde una perspectiva benévola.

Así la realidad de unos se convierte en la irrealidad de otros. Realidad y fantasía se mezclan para crear un mundo confuso en el que la diferencia inicial entre realidad e irrealidad pierde fuerza.

Aunque algunos críticos 10 presentan como una voz opuesta a la voz mágica de Clara, Esteban Trueba es otro personaje que se ve envuelto en un mundo mágico. En la primera parte de la novela, se nos presenta a Esteban Trueba como una oposición al mundo mágico de Clara. Esteban opina que "la magia, la religión y la cocina son asuntos propiamente femeninos."(133). Inclusive para dar mayor fuerza 
a esta oposición, se nos describe a Trueba como una persona que "espanta la naturaleza."(238)

No obstante, esta oposición desaparece en la segunda parte de la novela, cuando vemos que Trueba ha entrado en el mundo de los aparecidos y de los eventos irracionales. Así vemos como, cuando desentierra a Rosa para moverla al mausoleo que él ha destinado para ella, Trueba ve a su enamorada en la misma condición en que se encontraba el día de su entierro. El cuerpo de Rosa no deterioró con el tiempo, cuando Esteban la desentierra años después del envenamiento, la encuentra intacta. Una vez más se distorciona el tiempo, hay una oportunidad, gracias a lo mágico, de volver atrás, al mundo inventado por Trueba, en el que él es feliz. Pero esta oportunidad sólo dura segundos, ya que cuando Trueba la besa se hace polvo, una vez más Trueba vuelve a su realidad.

También vemos como Clara aparece en el lecho de su muerte.

Al principio era un halo misterioso, pero a: medida que mi abuelo fue perdiendo para siempre la rabia que lo atormentó durante toda su existencia, ella apareció tal como era en sus mejores tiempos, riéndose con todos sus dientes y alborotando a los espíritus con su vuelo fugaz. También nos ayudó a escribir y, gracias a su presencia, Esteban Trueba pudo morir feliz murmurando su nombre, Clara, clarísima, clarividente. (409)

Al mirar más de cerca al personaje de Trueba, vemos que esta tendencia a evadir realidades está presente desde antes del golpe militar. Lo que ocurrre es que la situación maravillosa a la que recurre Trueba, no es la misma a la que Clara se eleva. También Trueba tiene sueños que premonizan 
sucesos, como la muerte de su madre. Además Trueba crea su mundo propio, con la ayuda de la imaginación y el arte de otros.

Esteban Trueba se recostó en el respaldo tapizado en terciopelo rojo y agradeció la iniciativa de los ingleses de construir coches de primera clase, donde se podía viajar como un caballero, sin tener que soportar las gallinas, los canastos, los bultos de cartón amarrados con un cordel y los lloriqueos de los niños agenos. (51-52)

El uso de las técnicas narrativas descritas en estas páginas, como la yuxtaposición de relatos, los puntos de vista variados, la distorción del tiempo y el espacio, y la mezcla de realidad y "fantasía", ayudan a la escritora a crear un mundo confuso para el lector. En este mundo esconde su rebeldía contra los sistemas autoritarios tradicionales. El lector se ve obligado a participar activamente, a descifrar signos, convirtiéndose en cómplice del texto.

Unable to break the structures of state power, post-structuralism found it possible instead to subvert the structures of language. Nobody, at least, was likely to beat you over the head for doing so.14

Más importante aún, ha logrado crear una visión posmodernista15 de su mundo. El mundo de La casa de los espíritus

14 Terry Eagleton, 142.

15 "A familiar undertaking in postmodernist writings is to subvert the foundations of our accepted modes of thought and experience so as to reveal a 'meaningless' off existence and the underlying 'abyss', or 'void', or 'nothingless' on which pur supposed security is precariously suspended. In recent developments in linguistic and literary theory, there is an effort to subvert the foundations of language itself, so as to show that its seeming meaningfulness dissipates, for an unillusioned inquirer, into a play of unresolvable though conflicting indeterminacies." (Véase M.H. Abrams, A Glossary of Literary Terms) 
es uno en el que ya no gobiernan oposiciones binarias simples, sino que está lleno de perspectivas variadas. La realidad del mundo pos-modernista no se puede definir. Así queda reflejada la realidad existencial de los pueblos latinoamericanos. 


\section{ANALISIS A NIVEL TEMATICO-IDEOLOGICO}

Otras oposiciones binarias como la anterior, realidad/irrealidad, son expuestas por la narradora a través de todo su relato, pero esta vez las oposiciones no las encontramos en la técnica, sino en el contenido ideológico. En La casa de los espíritus se nos presenta una gama de relaciones ideológicas compuestas de ciertos significados que "son elevados a una posición privilegiada por ideologías sociales..."16 y sus opuestos.

Sin embargo, una vez establecidas estas oposiciones, Alba las destruye, añadiendo a éstas distintas perspectivas. Con esta práctica Alba parece convertirse en crítica posestructuralista de su historia.17 Las distintas perspectivas tienen el efecto de suavizar la oposición inicial y a veces destruirla.

16 Terry Eagleton, 142.

17 Ideas pos estructuralistas del filosofo francés Jaques Derrida: Deconstruction [nombre dado a esta práctica critica-literaria], has grasped the point that the binary oppositions with which classical structuralism tends to work represent a way of seeing typical of ideologies. Ideologies like to draw rigid boundaries between what is acceptable and what is not, between self and non-self, truth and falsity, sense and nonsense, reason and madness... Deconstruction tries to show how such oppositions, in order to hold themselves in place, are sometimes betrayed into inverting or collapsing themselves... Derrida is clearly out to do more than develop new techniques of reading: deconstruction is for him an ultimately political practice, an attempt to dismantle the logic by which a particular system of thought, and behind that a whole system of political structures and social institutions, maintains its force. Véase Eagleton Terry, 127-150. 
En La casa de los espíritus, Alba nos presenta distintas instituciones de autoridad social, como la Iglesia, la familia y el gobierno, que han sido tradicionalmente vistas como centros de la sociedad. ¿Existen verdaderamente estas instituciones? Y si existen, ¿qué significado o significados tienen, si alguno? Estas instituciones o los significados de las mismas nos las presenta Allende desde distintas perspectivas sin definir finalmente si existe una versión real. De esta manera queda retradado el caos que estas oposiciones causan en las mentes de un pueblo que se ve obligado a decidir entre significados opuestos, sembrándose así el odio que más tarde genera en violencia.

\section{LA IGLESIA}

A pesar de estar en contra de las ideologías que apoya la Iglesia, la familia del Valle asiste a ella.

Nívea prefería entenderse con Dios sin intermediarios, tenía profunda desconfianza en las sotanas y se aburría con las descripciones del cielo, el purgatorio y el infierno, pero acompañaba a su marido en sus ambiciones parlamentarias, en la esperanza de que si él ocupaba un puesto en el Congreso, ella podría obtener el voto femenino, por el cual luchaba desde hacía diez años. (11)

Severo, por su parte percibe la Iglesia como aliada del capitalismo. Para Severo la Iglesia es un negocio, ya que se lucra monetariamente de la prestación de sus servicios. Así, cuando el tío Marcos muere severo se niega a pagar las misas. 
Severo se opusó a la idea de mandar a decir algunas misas, porque no creía en ese recurso para ganar el cielo y mucho menos para volver a la tierra, y sostenía que las misas y las mandas, así como las indulgencias y el tráfico de estampillas y escapularios, eran un negocio deshonesto. (21)

Por medio de las voces de Nivea y Severo, grabadas en Ios cuadernos de Clara, Alba nos presenta una Iglesia católica defensora de ideologías conservadoras, capaz de infundir el terror divino mediante la violencia de los castigos de los pecadores. Esta iglesia imagina las más crueles y sangrientas torturas. Así se describen las imágenes de la Iglesia:

El único favorecido con el luto era el patrono de la iglesia, San Sebastián, porque en Semana Santa le ahorraba a los fieles el espectáculo de su cuerpo torcido en una postura indecente, atravesado por media docena de flechas, chorreando sangre y lágrimas, como un homosexual sufriente . . " (10)

Clara describe en sus apuntes el sermón del padre Restrepo donde condena a:

los fariseos que pretendían legalizar a los bastardos y al matrimonio civil, desarticulando la familia, la patria, la propiedad y la Iglesia, dando a las mujeres la misma posición que a los hombres. (11)

Clara, reta abiertamente a la institución eclesiástica al sugerir la existencia de una verdad distinta a la descrita por el padre Restrepo en sus sermones sobre los tormentos de los pecadores en el infierno. "Si el cuento del infierno fuera pura mentira, nos chingamos todos. . ." (14) El padre Restrepo la cataloga rápidamente como endemoniada y soberbia, 
como va a ser catalogada cualquier persona que trate de alterar la ideología de la clase dominante. Estas alusiones "sirven de dura crítica a prácticas religiosas retógradas e intimidatorias."18

Más tarde en la novela, se presenta una oposición a la Iglesia defensora de la ideología conservadora. El padre Dulce María, "un sacerdote español con la cabeza llena de ideas revolucionarias," (134) transforma las parábolas bíblicas en panfletos socialistas, ya que según él "la santa Madre Iglesia está a la derecha, pero Jesucristo siempre estuvo a la izquierda." (149)

En un momento de la narración pudiera parecer que Alba va a tomar una posición ante esta disyuntiva que favorecerá la Iglesia del tercer Mundo, ya que, después del golpe militar son los curas, como el padre Dulce María, los únicos que hacen algo por ayudar a las familias de los presos, Ios desaparecidos y los muertos. Sin embargo, Alba comenta que "comprendio que habían retrocedido a la antiguedad, cuando su abuela Clara iba al Barrio de la Misericordia a remplazar la justicia con la caridad." [sic] (360) Así quedan expuestas ambas versiones de la iglesia sin una tener más validez que la otra, ambas se confunden $y$ es difícil diferenciar una de la otra.

18 Teresa Huerta, "La ambivalencia de la violencia y el horror en La casa de los espititus," Chasqui 19-1 (1990): 58. 
Allende, al igual que Alba, se pone en contacto con la Iglesia después del golpe militar en su labor de ayudar a los presos políticos y sus familias. Confiesa que en ese momento se le revela otra Iglesia pero que no retoma su simpatía por ésta.

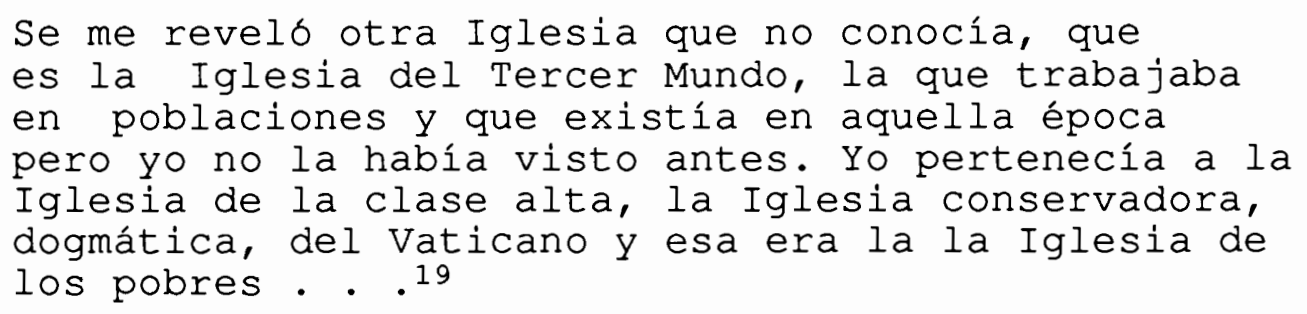

Ante los ojos de los que buscan una verdad, ambas Iglesias quedan convertidas en una sola, una institución que, aunque opuestas, apoya ideologías políticas y reemplaza la justicia por la caridad. Una para acallar la conciencia y el grito de protesta y otros para ganar la recompensa del cielo. La Iglesia católica deja de ser una respuesta para aquéllos que buscan sentido a su existencia.

Así comienzan algunos a buscar respuestas en otras alternativas. Clara y las tres hermanas Mora recurren al espiritismo, El Tío Marcos a la magia y Nicolás a prácticas religiosas orientales. De todas estas prácticas religiosas, ¿cuál contiene la verdad?

Las personas se ven obligadas a decidir. Unas siguen el camino que está a la derecha, otros el de la izquierda, y la mayoría quedan en el medio. Así pierde fuerza la oposición, y

19 Isabel Allende, entrevista, "Los cuentos de Eva Luna: El nuevo libro de Isabel Allende," 25. 
ya no es una amenaza para el poder que la instigó en primera instancia.

Así lo deja ilustrado Allende, cuando presenta a Jaime opinando que la religión es "la causa de la mitad de las desgracias del mundo," (211) ya que "el cristianismo, como casi todas las supersticiones, hacía al hombre más débil y resignado . . ." (211)

\section{LA ESCUELA}

La escuela también se nos presenta como manipuladoras de mentes e ideas. Nuevamente Alba presenta una oposición, esta vez entre la escuela del rico y la del pobre para luego desarticularla.

El oligarca Esteban Trueba desea que todos los niños del fundo Las Tres Marías aprendan a leer, a escribir y a sumar. Sin embargo, "no era partidiario de que aprendieran otros conocimientos para que no se les llenara la cabeza con ideas inapropiadas a su estado y condicion" (64) por un momento se presenta un lado bueno de Trueba, Trueba quiere educar a sus inquilinos. Pero inmediatamente interviene el lado malo; no quiere que aprendan ideas que los liberen de su explotación. Ambas partes de la oposición bueno/malo se encuentran en un punto común, una toca la otra, ya que el aparente lado bueno de Trueba lo que desea en realidad es que sus inquilinos adquieran más destrezas de las que él se pueda beneficiar. 
Desde esta perspectiva, ambas caras de la moneda se convierten en una, la del capitalista explotador.

En realidad, al construir las bases de su exitoso fundo, Trueba nunca quiso dar a los pobres $y$ desvalidos lo suficiente, haciendo gala de una conducta despótica que esparcía el terror por los alrededores. 20

Clara, aunque perteneciente a la oligarquía, hereda el deseo de difundir la caridad y la justicia. Así cuando llega a Las Tres Marías utiliza la escuela como medio de enseñar a los campesinos materias útiles y prácticas que los ayudarán con su lucha diaria. En la escuela Clara enseña a las mujeres a hervir la leche, curar la diarrea y blanquear la ropa. Pero además aprovechaba la reunión para aleccionar a las campesinas sobre sus derechos personales y legales. Por ejemplo les trataba de inculcar que la violencia doméstica no era natural y que los bienes del matrimonio eran comunes.

Por otro lado, los gemelos Trueba del Valle son internados en un colegio inglés victoriano, donde también se controlan sus ideas. En el colegio se corregían las ideas a "varillazos por el trasero." De los gemelos, el más que recibía castigo era Jaime, quien "se burlaba de la familia real británica y a los doce años estaba interesado en leer a Marx." (133)

En la universidad, donde la burquesía se entrmezcla con el pueblo, es donde las opuestas ideologías comienzan a

20 Teresa Huerta, "La ambivalencia de la violencia y el horror en La casa de los espíritus," Chasqui 19-1 (1990): 60 . 
friccionar y surgen nuevas alternativas. Así es como Alba queda expuesta a una nueva perspectiva, los pensamientos fascistas de su enamorado, Miguel.

Los estudiantes se llenan de nuevas ideas que surgen de sus fricciones. Las nuevas ideas son apoyadas por profesores como Sebastian García, quien "hacía arder en sus alumnos la llama que la mayoría vio apagarse cuando abandonaron la Universidad y se incorporaron al mundo que en su primera juventud creyeron poder cambiar." (306) Pero, según lo indica la cita anterior, esta diversidad de pensamientos sólo consigue disminuir la fuerza de la oposición inicial continuando así el estado inicial de control por parte de la clase dominante.

Ambas, la escuela oligarca y la campesina, se convierten en una misma, un lugar donde se tratan de infundir ideales sociales distintos, pero siempre partiendo desde la perspectiva dual ricos/pobres establecida por la clase dominante. Al igual que la iglesia, la escuela es una institución mantenida económica y moralmente por el poder económico. Por esta razón, el mundo de la educación también girará en torno a la oposición rico/pobre.

\section{LA POLITICA}

A través de todo su relato, Alba presenta oposiciones entre las ideologías partidistas de conservadores y 
Iiberales. Severo del Valle ambiciona ganar un escaño en el Congreso como candidato del Partido Liberal. Para lograr la candidatura de del Valle, el Partido tiene que "convencer a los humildes electores del sur."(31) Con esta pequeña descripcion de los electores, ya podemos adivinar que de los votos de la clase humilde depende el triunfo de los liberales.

Resulta irónico que Severo del Valle, quien pertenece a la clase dominante desee representar a los "humildes" en el Congreso. Del Valle alega estar interesado en sus obras, pero también se siente atraído por las "pompas" que representa tener una posición como ésta en el gobierno. La plataforma del Partido Liberal en esos años incluía ideas sufragistas y de igualdad de derechos para todos.

Los conservadores, quienes están en el poder en ese momento, no le perdonan esta acción y así se desata la cadena de asesinatos políticos que hasta ese momento "eran desconocidos en el país."(37) Severo paga su desafío con la muerte de su hija Rosa. No obstante, la familia se convierte por tradición en una "emancipada e intelectual." La familia parece rechazar toda forma de autoridad social.

Severo y Nívea del Valle desafían las reglas de las instituciones sociales, sobre todo la Iglesia. Perciben la autoridad como una imposición, pero están concientes de que para sobrevivir y triunfar en esa sociedad tienen que jugar por sus reglas. 
Después del envenenamiento de Rosa, un periódico del bando liberal publica una noticia "acusando veladamente a la oligarquía y añadiendo que los conservadores eran capaces hasta de eso, porque no podían perdonar a Severo del Valle que, a pesar de su clase social, se pasara al bando liberal." (37) Sin embargo, Alba aclara que la muerte de Rosa nunca se pudo descifrar, ni con "el celo de la policía, ni las pesquisas que realizó severo por su cuenta a través de un detective privado." (38)

Lo que sí se puede constatar en el texto es que el Partido Conservador es capaz de lanzar las más violentas amenazas y comentarios. Un ejemplo de esto es que cuando Nívea pierde su cabeza en el accidente del Covadonga, "sus enemigos ideológicos dijeron que si había perdido la cabeza en vida, [refiriéndose a sus ideas feministas] no había razón para que la conservara en la muerte."(120)

Según la ideología enemiga, Nívea pierde su cabeza debido a sus ideas liberales. Incluso Esteban Trueba, demócrata conservador, opina que "esa señora ha perdido la cabeza"(70), al pensar en las acciones que tomaban Nívea y sus amigas sufragistas para hacer llegar su mensaje a las instituciones gubernamentales. Nívea "se encadenbaba con otras damas en las rejas del Congreso y de la Corte Suprema...pidiendo que las mujeres tuvieran los derechos de los hombres..."(70) 
De esta manera la cabeza de Nívea se convierte en un símbolo. Para sus enemigos es algo que tenía merecido pero que tienen que esconder, como vemos más adelante cuando clara encuentra la cabeza en un campo de cebollas y Esteban Trueba la esconde para evitar el escándalo. Para los liberales se convierte en una amenaza cruel.

Posterior a la época de intervención de los del Valle en la vida política del país, se presenta al lector el envolvimiento político conservador de Esteban Trueba y las nuevas ideas que van llegando de Europa para alimentar las mentes liberales.

Esteban Trueba siempre había tenido convicciones políticas muy fuertes. Es él quien nos hace llegar la teoría de los "fuertes y los débiles".

- ¡Justicia! ¿Es justo que todos tengan 10 mismo? ¿Los flojos lo mismo que los trabajadores? ¿Los tontos lo mismo que los inteligentes? ¡Eso no pasa ni con los animales! No es cuestión de ricos y pobres, sino de fuertes y débiles. Estoy de acuerdo en que todos debemos tener las mismas oportunidades, pero esa gente no hace ningún esfuerzo. ¡Es muy fácil extender la mano y pedir limosna! Yo creo en el esfuerzo y en la recompensa. Gracias a esa filosofía he llegado a tener lo que tengo. Nunca he pedido un favor a nadie $y$ no he cometido ninguna deshonestidad, 10 que prueba que cualquiera puede hacerlo. Yo estaba destinado a ser un pobre infeliz escribiente de Notaría. Por eso no aceptaré ideas bolcheviques en mi casa. (134)

La teoría de Trueba hubiese resultado convincente si antes no se hubiesen mencionado en el relato los abusos del patrón del fundo Las Tres Marías contra de sus inquilinos. 
Alba nos presenta la soberbia y el poder ilimitado de su abuelo como un obstáculo que nunca hubiese permitido a los campesinos adelantar en la carrera de las clases sociales.

A pesar del arduo trabajo de los inquilinos, Trueba no era capaz de pagarles un sueldo decente, sino que "impuso un sistema de vales. . que con el tiempo llegó a remplazar al dinero legal." [sic] (64) Los inquilinos se convierten en esclavos del patrón. Los horarios de trabajo son exagerados. Trueba se convierte en un miembro capitalista de la sociedad que llega al extremo de la explotación. Encima de todo, Trueba no respeta la dignidad del campesino, sino que por el contrario "no pasaba ninguna muchaha de la pubertad"(67) sin que Trueba la abusara sexualmente.

Es en esta época que comienzan a llegar de Europa "ideas subversivas, traídas por los vientos incontrolables de la radio, el telégrafo y los buques cargados de emigrantes"(71) que vienen escapando a los estragos de la guerra. Estas ideas dan empuje a la ola de desconteno que agitaba al país. Ante la frustración causada por la oposición binaria entre una clase social alta y una baja, la gente comienza a buscar nuevas opciones. Se forman nuevos partidos de izquierda y sus ideas comienzan a infiltrarse en los fundos. Los delegados de estos nuevos partidos "entraban disfrazados de evangélicos, con una biblia en un sobaco y sus panfletos marxistas en el otro" (72) para predicar sobre la revolución. 
Desde las nuevas perspectivas la oposición rico/pobre pierde sentido

Es ante esta amenaza que Esteban Trueba se inmiscuye indirectamente en los asuntos políticos. Comienzan las reuniones en "el club" que culminan en planes para hacer votar a los campesinos por los candidatos conservadores.

Esteban Trueba, al sentirse amenazado comienza, junto a otros miembros del partido conservador, sus gestiones para arrastrar a los campesinos a respaldar su lado ideológico. Así es cómo:

Les dieron una fiesta. . . y les prometieron que si salía el candidato conservador tendrían una bonificación, pero si salía cualquier otro se quedaban sin trabajo. Además controlaron las urnas y sobornaron a la policía. (73)

Alba demuestra cómo, tanto los nuevos partidos izquierdistas como el antiguo partido demócrata conservador, se valen de distintas artimañas (como las antes mencionadas) para ganar las mentes y los votos del campesinado. Ambos extremos ideológicos persiguen el mismo propósito, ganar el poder; aunque 10 disfracen unos debajo del progreso y otros debajo de la caridad y la "justicia".

Todos se convierten en víctimas del sistema que sólo busca la conquista del poder. De esta manera las oposiciones entre partidos políticos quedan disipadas. Ante la confusión y la frustración generada por esta diversidad de pensamientos, comienzan a acumularse odios y deseos de venganza. Cada grupo expresa estos sentimientos de manera 
distinta. El Partido Conservador comienza a deliberar una violencia verbal que más tarde genera en otro tipo de violencia. Ésta es quizás la única oposición que Allende no destruye en su texto. La escritora parece estar muy firme en su opinión de que en "toda la violencia ha provenido siempre del gobierno pero no se puede decir que haya terrorismo en Chile."21

Sin embargo, más adelante se nos presenta la figura de Miguel, un joven estudiante universitario que hablaba de la revolución y decía que "a la violencia del sistema había que oponer la violencia de la revolución." (303) Así se ve cómo los estudiantes toman un edificio de la Universidad en apoyo a una huelga de trabajadores. Pero Alba presenta esta acción como una pacífica de parte de los estudiantes que sólo tienen la intención de transformar el edificio en una fortaleza con fines defensivos, $y$ en ningún momento ofensivos. Su ofensiva se limita a pintar pancartas y otros métodos pacíficos de protesta.

Pedro Tercero García, hijo de administrador de Las Tres Marías, es uno de los campesinos que comprende y propaga las nuevas ideas izquierdistas, que desafían la autoridad del patron. Esteban reacciona a este desafío violentamente. Lo azota "con una fusta. . porque llevó a los inquilinos las novedades que andaban circulando entre los sindicalistas del pueblo..." (150) Sin embargo, celebra las gestiones

21 Isabel Allende, Entrevista, La Tortuga 27. 
sindicalistas de Tránsito soto, que son idénticas a las de Tercero García. Inclusive la ayuda en su empresa, ya que ve en sus ojos la misma ambición suya.

La mayoría de los campesinos, por otro lado, se nos presentan como seres obligados a la resignación por el miedo y la ignorancia. Así vemos cómo cuando Pedro Tercero se queja de las injusticias de la vida, su padre, Pedro segundo, le dice que "siempre ha sido así. . usted no puede cambiar la ley de Dios."(158)

Esteban Trueba despide a Pedro Tercero. Ante los ojos de los campesinos, Tercero García se convierte en héroe, mientras que ante los ojos de los patrones de la región, se convierte en prófugo.

Pedro Tercero García continúa su "laborioso proceso de educar al pueblo" (316), ya que la educación, es lo único que va a salvar al pueblo de la confusión creada por el poder imperialista. Pedro Tercero García utiliza su música para lograr sus propósitos y los logra. "Tal y como lo había pronosticado el Candidato, los socialistas, aliados con el resto de los partidos de izquierda, ganaron las elecciones presidenciales." (322)

Este triunfo toma a los conservadores por sorpresa, ya que estaban confiados en que la confusión creada por el multipartidismo, la mezcla de realidades distintas, no permitiría esta victoria. Por eso los correligionarios del Senador Trueba le aseguran a éste que 
el marxismo no tiene ni la menor oportunidad en América Latina. ¿No ves que no contempla el lado mágico de las cosas? Es una doctrina atea, práctica y funcional. ¡Aquí no puede tener éxito! (291)

Cuando los socialistas superan sus diferencias con el resto de los partidos izquierdistas y ganan control, los de derecha se sienten amenazados y rápidamente toman acción.

Mientras el nuevo gobierno busca crear una buena imagen y asegurar su popularidad, la derecha busca maneras de desprestigiarlo. Así es que Esteban Trueba se ingenia la idea de eliminar al nuevo presidente. Con este fin se reúne con;

politicos, militares y con los gringos enviados por el servicio de inteligencia, para trazar el plan que tumbaría al nuevo gobierno: la desestabilización económica, como llamaron al sabotaje. (325)

Por su parte, Alba parece pensar que el Partido Socialista, una vez en el poder falla en dar reconocimiento a sus héroes. Así es que el hombre que estuvo dispuesto a dar su vida por la causa del socialismo, ya no es visto como un héroe, sino como un simple campesino que puede seguir ayudando al partido con su espíritu trabajador y su popularidad, que el partido desea seguir explotando.

Pedro Tercero García queda desilusionado de las organizaciones políticas. Así mientras otros, como Miguel se dedicaban a defender el triunfo, Pedro Tercero García no encontraba la fuerza física ni moral para continuar la lucha.

Así fue como se encontró sentado detrás de un escritorio por primera vez en su vida, con una secretaria para su uso personal y a sus espaldas un grandioso retrato de los próceres de la Patria en alguna honrosa batalla. Pedro Tercero García 
miraba por la ventana con barrotes de su lujosa oficina... No era un cargo decorativo. Trabajaba desde las siete de la mañana hasta la noche y al final estaba tan cansado, que no se sentía capaz de arrancar ni un acorde de su guitarra . . (327)

Luego del golpe militar, Pedro Tercero no comparte la suerte de otros que se entregan. Se siente como un traidor pero finalmente ve una oportunidad de libertad, que es 10 único que le importa en ese momento, y la aprovecha. El Senador Trueba lo ayuda a escapar con su hija, Blanca, y se van a vivir en el exilio.

Por otra parte, Esteban Trueba, el democráta conservador, también se convierte en víctima del sistema por el cual lucha. En su madurez Esteban Trueba decide envolverse directamente en la política y así decide convertirse en el Senador Trueba. Se dedica a su campaña política y pone su propia fortuna al servicio de su causa.

El Partido Conservador tampoco aprecia la labor de Trueba, él mismo compra su posición, el gobierno realmente no Io respalda económicamente. Aún así, Trueba continúa su empeño en enmendar con sus ideas el destino de su país. Más tarde vemos cómo se convierte casi en un estorbo para el Partido, el cual lo ridiculiza y hasta intenta deshacerse de él.

El Presidente de la República lo llamó a su oficina para ofrecerle la embajada en Suiza, donde podría tener un cargo apropiado para sus años que le permitiera reponer su salud. (292)

Vemos cómo ante los ojos de la narradora, tanto el Senador como el cantante se convierten en instrumentos de sus 
respectivos partidos políticos. Éstos los emplean hasta que ya han logrado sus propósitos y luego, cuando ya no les son útiles los quieren relegar a una posición de poca importancia. Ambos sienten tener la verdad conveniente para su patria, pero no se dan cuenta de que es un poder mayor, el poder imperialista el que domina el destino de su patria, ambos se convierten en marionetas del poder económico.

De esta manera, la oposición Esteban Trueba/Pedro Tercero García pierde fuerza y ambos quedan en un término medio, donde se reconcilian no ideológica pero moralmente. No pasa así con la lucha por el trono de la presidencia. La oposición se hace más cruda que nunca, esta vez la confusión que trata de infundir el poder económico en el pueblo no está dando resultado, ya que:

el pueblo que estaba habituado a la pobreza y que no había comido pollo más que para las fiestas patrias y la Navidad, no perdio la euforia del primer día, al contrario, se organizo como para una guerra, decidido a no permitir que el sabotaje economico le amargara el triunfo. (331)

\section{LA DICTADURA}

El poder imperialista decide entonces tomar acción más severa. Ya no se trata de una simple lucha de clases e ideologías creada por el mismo poder capitalista, sino de un desafío real. Ante la amenaza, igual que lo hizo antes Trueba, el poder económico reacciona con furia. "Entonces 
oyeron el rugido de los aviones y comenzó el bombardeo." (349)

El Esteban Trueba que antes "condena" las dictaduras, colabora con el golpe militar. En realidad, Trueba siempre estuvo de acuerdo con la idea de ejercer control sobre las masas mediante el uso de Las Fuerzas Armadas. Aunque describe el país como uno diferente,
una verdadera república, tenemos orgulio cívico, aquí el Partido Conservador gana limpiamente y no se necesita a un general para que haya orden $y$ tranquilidad, no es como esas dictaduras regionales donde se matan unos a otros, mientras los gringos se llevan todas las materias primas, (73)

vemos que en realidad son Las Fuerzas Armadas quienes "garantizaron el proceso democrático" (73) en cada elección.

Una vez los militares recobran el poder para la derecha, comienza el 'restablecimiento del orden'. Este orden no iba de acuerdo a lo esperado por la oligarquía, ya no están en el poder, sino que los militares con la ayuda del poder capitalista norteamericano se apodera de él. Por esta razón es que Trueba se arrepiente de su acción.

En una noche surgieron por encantamiento jardines recortados y macizos de flores en las avenidas, plantados por los cesantes para crear la fantasía. de una pacífica primavera." (361)

Vemos cómo, al igual que Trueba hizo en el fundo, el nuevo régimen disfraza el abuso del poder con el progreso. Pero en este caso se borran las diferencias de clases, el pueblo en general es la nueva víctima del abuso. 
El inventado pacifismo duraba hasta que alguien intentaba escribir mensajes políticos en la vía pública, ya que esto "era penado con una ráfaga de ametralladora en el sitio." (361)

La alta burguesía se sintió feliz, y cuando le surgieron algunas dudas, la dictadura comenzó a devolverles las tierras que la reforma agraria había repartido. Así vemos como el juego comienza nuevamente. Sólo que esta vez, se nos presentan nuevas reglas impuestas por los militares con el poder de las armas norteamericanas.

Una gran parte de la clase media se alegró con el Golpe Militar, porque significaba la vuelta al orden, a la pulcritud de las costumbres... pero pronto empezó a sufrir el tormento de los precios altos y la falta de trabajo. No alcanzaba el sueldo para comer. (365)

La oposición rico/pobre queda establecida una vez más y así todo está en orden. Sin embargo, para asegurar que el orden es definitivo, se establece la censura y el castigo severo a quien la desafíe. El golpe militar:

establece un paréntesis 'autoritario' que garantiza un retorno al sistema tradicional de franquicias burguesas," e "impone un modelo desatinado a reorganizar mesiánicamente el conjunto de la sociedad desde sus estamentos sociales hasta sus orientaciones ideologicas. (Epple, 36)

\section{LOS MILITARES}

Conocemos la imagen que de los militares tiene Alba, a través de las intervenciones de éstos en los relatos de 
distintos acontecimientos. En el primero de estos acontecimientos se nos presenta a la Fuerza Armada 'garantizando' el proceso democrático durante unas elecciones partidarias. Según el tono irónico de Alba en este relato, se hace evidente que en relidad los militares están allí para amedrentar a los votantes que piensan votar por la oposición.

En esta ocasión Las Fuerzas Armadas están bajo el control del gobierno demócrata. La imposición del pánico mediante la amenaza de las armas es una táctica que utilizan los militares apoyados por la oligarquía y que más tarde se vuelve en contra de ésta.

Más tarde, cuando la naturaleza vibró, los soldados se hacen cargo del desorden. La manera en que tratan de poner fin al desorden es una desordenada por sí. Los soldados "fusilaban sin más trámites a quienes sorprendían robando..." (156) Los ladrones no hacían otra cosa que buscar riquezas entre los escombros.

La fuerza policiaca no hace otra cosa que velar por el orden establecido por la oligarquía. El cuerpo es parte del gobierno, tiene, por obligación, los mismos fines de velar por los intereses de los que están en el poder. Los militares resienten la falta de poder propio. Así queda ilustrado cuando la narradora dice que Esteban García "en su profesión había aprendido la lección de que había otros muchos más poderosos que él y que no podía darse el lujo de actuar con impunidad." (309) 
Bajo el uniforme militar, la violencia es permitida y hasta promovida en ciertas ocasiones. Los miembros de la fuerza uniformada se acostumbran a esta violencia, que en parte se debe al odio que el propio sistema ha creado entre dos grupos. No obstante, cuando la violencia se torna en contra de los suyos propios la oligarquía reacciona, ahora la ve desde otra perspectiva. El poder que ellos mismos han creado, los traiciona, y no hay nada que puedan hacer.

Pero antes de imponer su poder, el partido socialista tiene su 'oportunidad', aquí vemos a unos militares distintos. Así lo ilustra Alba con el relato en que los carabineros son enviados por el nuevo Presidente socialista a rescatar al Senador Trueba. Trueba ha sido tomado como rehén por sus inquilinos de Las Tres Marías. Los nuevos propietarios del fundo impiden, por medios legales, la entrada de las Fuerzas Armadas a Las Tres Marías. Pero los policías se quedan allí. Cuando llega Pedro Tercero García a rescatar al Senador, junto a Blanca y a Alba, encuentran:

en el portón del fundo un gentio en amigable charla alrededor de una fogata donde se asaba un cerdo. Eran los carabineros, los periodistas, los campesinos que estaban dando el bajo a las últimas botellas de la bodega del senador.(340)

Los miembros de la policía eran en su mayoría las mismas personas del pueblo. En este caso no recurren a la violencia, ya que las oposiciones binarias han sido destruidas temporeramente, durante el corto periódo en que los partidos izquierdistas se hacen aliados para ganar las elecciones. 
Todos son compañeros en ese momento, no se sienten controlados por un gobierno oligárquico, la supuesta libertad les da tranquilidad. El odio y la violencia se apaciguan.

Es ahora, Miguel, un joven izquierdista, quien piensa que hay que defender el poder recién adquirido. Por esta razón comenta que "ganamos, pero ahora hay que defender el triunfo." (324)

Aunque en el período socialista la milicia parece haber controlado su violencia, vemos cómo la derecha se encarga de echar leña al fuego para conseguir sus propósitos de derrocar el gobierno socialista que ya ha comenzado a despojar a los terratenientes de sus propiedades. Es así como comienzan las reuniones clandestinas, como antes las tenían los socialistas, con los militares y los gringos del servicio de Inteligencia. De estas reuniones surge el plan de la desestabilización económica "como llamaron al sabotaje." (325)

Después del golpe militar, Trueba, extrañado de que no lo hubieran llamado a participar del nuevo gobierno se dirige al Ministerio de Defensa.

El oficial me recibió con las botas sobre el escritorio, masticando un emparedado grasiento, mal afeitado, con la guerrera desabotonada... procedió a pedirme las llaves del automóvil con el argumento de que se había clausurado el gobierno. (355)

Los que hasta el momento se habían visto controlados por el Congreso, ahora ven la oportunidad de controlar. Una vez en el poder utilizan las mismas tácticas que la oligarquía 
utilizo anteriormente con la clase baja. Cambian la justicia por la caridad para los ricos y controlan la oposición mediante la imposicion del terror. Resurge el abuso y la violencia en formas más terribles que las anteriores.

Una vez más vemos disiparse las oposiciones, esta vez la oposición entre la dictadura militar y el gobierno demócrata. Ambos persiguen el poder y cuando lo obtienen utilizan las mismas táctias para mantenerlo. Aquí queda expuesto el círculo vicioso que crea el poder dominante con el establecimiento de oposiciones binarias tradicionales. Se ve una vez más que la variedad de perspectivas creadas por elementos opuestos no permiten el verdadero cambio social. Esta circularidad creada por la manera tradicional de percibir la sociedad es la que Alba pretende eliminar con su análisis deconstructivo.

"Alba se pregunta de adónde habían salido tantos fascistas de la noche a la mañana..." (363) Para comprender esto expone la hisoria de Esteban García y la de propio Esteban Trueba, que en el mundo que invento en Las Tres Marías fue un dictador violento y cruel. Así excusa en cierto sentido las acciones de su abuelo y Esteban García, descartando la idea de que tome una posición opuesta ante esta situación.

Abuelo y nieto crecieron en la pobreza, Esteban García es una persona envenenada por el odio:

Pancha García, antes de morir alcanzó a envenenar su infancia con el cuento de si su padre 
hubiera nacido en el lugar de Blanca, Jaime o Nicolás, habría heredado Las Tres Marías y podría haber llegado a Presidente de la República, de haberlo querido. En aquella región sembrada de hijo ilegítimos $y$ de otros legítimos que no conocian a su padre, el fue probablemente el único que creció odiando su apellido. Vivió castigado por el rencor contra el patrón, contra su abuela seducida, contra su padre bastardo $y$ contra su propio inexorable destino de patán. (182)

Su odio lo exterioriza a través de la violencia. Así vemos cómo cuando muere su bisabuelo Esteban García se encuentra "ocupado en ensartar los ojos a un pollo con un clavo" y hasta trata de pinchar los ojos del cadáver. Cuando crece, es Esteban García, quien es manejado por la avaricia y la falta de reconocimiento traiciona a su primo, Pedro Tercero García. Esteban García delata el escondite de su primo. Trueba necesita vengar la virginidad de su hija y trata de comprar un instrumento que le ayude a conseguir el escondite del violador. Este instrumento es Esteban García.

Esteban García por su parte, aprovecha la recompensa que, aunque tarde, recibe del patrón y la convierte también en instrumento para lograr sus propósitos de venganza.

Abuelo y nieto siguen los mismos patrones. Esteban Trueba y Esteban García han tenido una niñez llena de necesidades y odios contra su familia y el mundo. Ambos recurren a la violencia para exteriorizar su malestar.

Al ganar poder y control todos estos demonios se manifiestan. Así es como Esteban Trueba se desquita las miserias de su vida con los inquilinos y los animales de Las 
Tres Marías, Esteban García se desquita contra los presos políticos.

En el plano personal, Trueba mutila a Pedro Tercero García cobrando la virginidad de su hija Blanca. pero antes él había violado a la abuela de Esteban García y nadie lo había hecho pagar. Aunque es el propio Esteban García quien delata el escondite de su primo, más tarde hace que el abuelo pague sus culpas. Lo hace violando y torturando a Alba. Unos se vengan de los otros, vengándose de ellos mismos. Así se convierten en traidores y traicionados. Esta frustración y rabia que llevan reprimida es la que explota al tener el poder de las armas.

Todo el odio acumulado por el pueblo, debido a las oposiciones de clases, explotan en la violencia. Por consiguiente, la violencia es una dimensión que siempre está presente pero que se manifiesta cuando la persona se siente en control.

It can be triggered by a little excuse, by something very small, and the facists will take over. The people who are self-righteous who have the weapons and who think that they have the truth, they need a very little excuse to take hold. 22

22 Isabel Allende, "Interview with Isabel Allende," Confluencia 6-1 (1990): 100 . 
LA FAMILIA Y LA SOCIEDAD

Otra institución social que se nos presenta es la familia. De hecho, toda la primera parte del libro constituye la saga familiar de los Trueba del Valle. esta saga familiar es una representación simbólica de la evolución historico-política, y a la vez ideologica de la sociedad chilena. Esta evolución se presenta desde distintas perspectivas y sin definir la validez de ninguna de éstas. De hecho, la crítica ha señalado que "Chile, espacio que trasluce sin nombrarse, se convierte en una gran casa donde flotan los espíritus de miles de muertos . . "23

Desde las primeras páginas vemos que en la sociedad de La casa de los espiritus existen dos mundos opuestos, el mundo de los ricos y el mundo de los pobres. Esta oposición no sólo instiga las demás oposiciones expuestas en este estudio, sino que a la vez las resume. Los puntos medios que surgen para esta oposición desaparecen, y es precisamente por esta razón que esta sociedad termina por vivir los acontecimientos de violencia que marcan su historia.

En la familia, el primer eslabón son los del Valle. Esta familia se sitúa en una sociedad simplista, casi primitiva, en la parece existir una oposición dual para todos los ordenes. En esta sociedad todo es blanco o negro, hay conservadores o liberales, ricos o pobres, hombres o mujeres. Sin embargo, ya

23 Mario A. Rojas, 919. 
se comienzan a buscar otras alternativas. Las mujeres de esta sociedad quieren destruir estas diferencias, dando los mismos derechos a todos.

La generación que sigue, ve otras alternativas a estas oposiciones duales, pero prefieren quedar al margen de toda acción. Clara lleva en su subconciente estas ideas revolucionaris que hereda de su madre, pero sólo se manifiestan en disminuidas ocasiones. Esta generación parece sentirse a gusto en su torre de marfil y no quiere responzabilisarse con la causa social.

A esta visión social, se une, por matrimonio, la visión de una sociedad capitalista, representada por Esteban Trueba. Esta sociedad ve la diferencia de clases como una escalera, la que trabajando arduamente se puede subir hasta llegar al tope. Aún en esta sociedad hay una visión dual del mundo, pero las personas supuestamente pueden cruzar de un lado a otro con el esfuerzo de su trabajo. Sin embargo, esta teoría no funciona en la práctica. Vemos en la novela que sólo unos pocos suben un escalón social, pero además de su esfuerzo necesitan padrino, alguien que pertenezca a la clase alta tiene que darles el empujón necesario para lograr el salto. Esteban Trueba no tiene riquezas, pero se vale del "prestigio del apellido de mi madre, que sirvio para que el Banco me diera una fianza."[sic] (31) Esteban García, por su parte, adquiere una recomendación del senador Trueba, con la que puede ingresar a la escuela de carabineros. 
Lo que ocurre, como se ve con ambos, Trueba y García, es que al llegar al tope, abusan del nuevo poder, y así comienza la explotación. Esteban Trueba es uno de los pocos que logran cruzar al otro lado. En su niñez padece la pobreza y culpa a su madre por haberse casado fuera de su círculo social. "Trueba no había sido más que un accidente en la vida de doña Ester, que estaba destinada a casarse con alguien de su clase . . " (51)

Esteban Trueba se promete que nunca va a volver a ser pobre y así llega a las minas de oro. Siente la necesidad de ser rico para estar al mismo nivel de su prometida, Rosa del Valle. Después de la muerte de Rosa, no merma su deseo de riqueza. Trueba va a Las Tres Marías. Cuando se ve con un nuevo poder, que antes no había experimentado, Trueba comienza a ver a los pobres casi como animales. Tiene la idea de los pobres no son seres pensantes, por 10 que él tiene que hacerse cargo de ellos. Al único que ve diferente es a Pedro Segundo García, pero sus prejuicios sociales le impiden aceptar al campesino como igual.

A consecuencia de este abuso de poder, comienzan a surgir nuevas alternativas a esta sociedad capitalista. Pedro Tercero García, quien viene a formar parte de la familia al convertirse en el padre de la nieta de Trueba, representa las nuevas ideas sociales. Pedro Tercero García habla de sindicatos, de ideas marxistas que también llegan desde Europa, los pobres comienzan a soñar con el establecimiento 
de un sistema social de igualdad. Surgen nuevas perspectivas. El mundo ya no es blanco y negro, pero aún tiene dos caras representadas en Jaime y Nicolás. En la clase alta hay personas como Jaime, conciente y aliado de las nuevas ideas sociales, personas como Nicolás, enajanadas de otras realidades que no sean la suya propia y aquéllos como Blanca que, aunque concientes de las injusticias sociales no quieren dejar su círculo y su comodidad. En la clase baja, también se nos presentan variedad de perspectivas. El pobre conformista, el que siente miedo a la rebelión expone al lector "un esquema político-social que se perpetua por el terror y la ignorancia." (Huerta,60) Del otro lado estan los que creen que la violencia es la única manera de cambiar el sistema social, como Miguel. Así comienza a complicarse una sociedad que antes fue simplista.

Otras perspectivas son las distintas visiones que sobre sí mismos tienen los pobres. Pedro Segundo García consideraba partirse "el lomo por volver a poner en pie la riqueza del patrón" era algo natural, "la ley de Dios." (158) Este es el punto medio en que las distintas instituciones establecidas por la clase dominante, mantienen a las masas para controlarlas. Vemos cómo las enseñanzas de la Iglesia y la falta de educación influyen en la visión que pedro segundo tiene de sí mismo. 
Por otro lado, su hijo, Pedro Tercero García, representa al pobre que logra educarse. Blanca enseña a Tercero García a leer. Pedro Tercero García

leyó y releyó mil veces los libros mágicos de los baules del tío Marcos, y siguió alimentándose con otros que le prestaban los sindicalistas del bar y el padre José Dulce María, quien también le enseño a cultivar su habilidad natural para versificar $y$ a traducir en canciones sus ideas. (149)

Mientras los campesinos como Pedro Segundo no representan amenaza para la oligarquía, el surgimiento de campesinos como el hijo del administrador de las Tres Marías preocupa a algunos como Esteban García. Por esta razón es que el campesino es azotado por su patrón. Aquí vemos otro tipo de pobre, la Nana, quien ante el incidente antes mencionado comenta en forma burlona: "Aprende, mocoso, a meterte con los de tu clase y no con señoritas."(150) Esta visión también es la de la resignación. La Nana está tan acostumbrada a servir a esta familia que ya no sabe la diferencia, no sabe si es parte de ella o una simple empleada, pero le gusta imaginar que sí es considerada parte de la familia oligarca.

Esteban García presenta otro punto de vista sobre la pobreza. El joven ha crecido añorando rabiosamente lo que debio pertenecerle. La oposición entre riqueza y pobreza causa en él rencor, codicia, violencia, pero a la misma vez causa miedo e impotencia.

El joven recorrió la habitación con la vista, sin atreverse a hacer ningún movimiento, rumiando el rencor de que todo aquello podría haber sido suyo, si hubiera nacido de origen legítimo... Miró la biblioteca sintiéndose sofocado... Se estremecio 
de odio y de temor. Nunca había estado en un lugar así, y hasta ese momento pensaba que lo más lujoso que podía existir en todo el universo era el cine de San Lucas, donde una vez la maestra de la escuela llevo a todo el curso a ver una película de Tarzán. (271)

También se nos presenta la visión de jóvenes, como Miguel, quienes creen que una revolución es lo único que va a terminar con estas diferencias. Pero ellos también se ven como opuestos a las clases altas. Sus teorías también se basan en la diferencia entre clases, también persiguen la conquista del poder.

La oligarquía también difiere en sus visiones de la rebeldía de algunos campesinos. Así, mientras Trueba se preocupa y toma acción, la mayoría de las familias ricas seguian ocupadas en fiestas. Algunas personas, como Blanca, comprenden la situación y la lucha de los pobres. Sin embargo, la comodidad que sienten en su círculo no les permite salir de él. Es por eso que, a pesar de las proposiciones matrimoniales de Tercero García, Blanca no se decide a huir con el hombre a quien supuestamente ama. Incluso, cuando sale encinta de Alba sigue la voluntad de su padre de casarse con el conde Santigny. En esta ocasión Esteban Trueba opina que:

sería igual si ella daba a luz un bastardo, que si se casaba con el hijo de un campesino: la sociedad la condenaría al ostracismo en cualquiera de los dos casos. (203)

Blanca parece estar de acuerdo con las ideas de su padre, ya que tampoco quería quedar excluida de su círculo social. 
Otro punto de vista acerca del pobre, es el de los mellizos. Jaime se solidariza enteramente con la causa del necesitado. "Todo el dinero que le daba su padre iba a parar a los bolsillos de los indigentes que atendía en el hospital." (210) Por su parte, Nicolás vive al margen de las necesidades agenas.

La pobreza le parecía un concepto abstracto y lejano, aplicable a los inquilinos de Las Tres Marías y los indigentes que su hermano Jaime socorría, pero con los cuales él nunca había estado en contacto. (223)

Al enfrentarse a la pobreza de su amante, Amanda, Nicolás recuerda los cuentos de la infancia de su padre, y "por primera vez pudo encajar esas anécdotas didácticas con una realidad" y siente el deseo de protegerla. Sin embargo, lo que hace es ayudarla a abortar su propio hijo y alejarse de ella.

De esta manera podemos apreciar cómo la confusión entre distintas perspectivas ayuda a quitar fuerza a una verdadera oposición, hay pobres que se ven como ricos, otros se conforman con su situación convencidos por instituciones sociales como la iglesia, otros se rebelan. Hay ricos que se ven como pobres, otros que se compadecen pero no actúan, otros que remedian la rebeldía de éstos mediante la fuerza.

No obstante, llega un período en esta historia en el que los humildes logran salvar diferencias y se apoderan del poder. En cuanto lo adquieren comienzan a dividirse nuevamente, lo que en parte contribuye a su fracaso. 
Así, el juego del poder capitalista comienza nuevamente. Se establece una dictadura militar que hace la oposición inicial ricos/pobres más rígida que nunca, la historia simplemente va en círculos repitiéndose hasta la eternidad, ya que todos persiguen un fin común, el poder.

En esta sociedad de perspectivas variadas nace Alba, la última rama del árbol genealólico de la familia Trueba-del Valle. Alba, durante la primera parte de su vida, está enajenada de realidades distintas a la suya en la gran casa de la esquina. Es el amor por Miguel lo que la hace despertar a otras realidades, a otras perspectivas de vida.

Pero es el azote del golpe militar el que la hace reaccionar. Alba se convierte en representante de otra formación social que emerge de la confusión y el dolor que causa la violencia de este evento. El mundo de Alba ya no es un lugar seguro, su mundo también se convierte en un "caleidoscopio de espejos desordenados", pero en este mundo, es todo tipo de violencia y de tortura lo que puede ocurrir. A consecuencia de estos sucesos imaginables, Alba intenta poner su mundo en orden, y por esta razón comienza su escritura. Sin embargo, su interés ya no es dar un nuevo nombre a la historia antigua, sino explorar las posibilidades de establecer una nueva organización social que difiera en todo a las formas antiguas basadas en las oposición dual entre ricos y pobres. Por eso es que al final Alba dice: quiero pensar que mi oficio es la vida y $\mathrm{mi}$ misión no es prolongar el odio, sino sólo llenar 
estas páginas mientras espero el regreso de Miguel, mientras entierro a mi abuelo que ahora descansa a mi lado en este cuarto, mientras aguardo que lleguen tiempos mejores, gestando a la criatura que tengo en el vientre, hija de tantas violaciones, o tal vez hija de Miguel, pero sobre todo hija mía. (409-410)

Alba no quiere prolongar la historia que promueve el odio, no quiere formar parte del círculo vicioso que forman las oposiciones duales. Quiere llenar las páginas, quiere hacer y completar su análisis, su examen del pasado para no cometer los mismos errores que sus antepasados cometieron. Así logrará tiempos mejores. Lo primero que encuentra necesario es dejar los odios causados por la oposiciones iniciales atrás, para poder comenzar algo verdaderamente distinto. Comienza por destruir la primera oposición de la nueva vida que lleva dentro. La oposición hija de las violaciones/hija de Miguel se disipa ante el hecho de sobretodo ser hija suya.

Sin embargo, luego de esta aseveración, termina su narración con las mismas palabras conque la comienza, lo que crea confusión en el lector, ya que no se puede asgurar entonces que Alba vea una salida a la circularidad de su historia. ¿Podrá surgir una "nueva forma social, que se distinga de la 'permanente revolución' de las sociedades poscapitalistas"? Hasta este punto el lector hubiera podido llegar a la conclusión de que el interés de Alba al examinar las tendencias de las sociedades pos-capitalistas (donde surge la variedad de perspectivas), "era la posibilidad del 
establecimiento de una sociedad pos-modernista-con un nuevo principio histórico de organización social." 24 sin embargo, vuelve al comienzo de su narración, perdiendo significado esta intención. Alba se dedica a llenar páginas sin una intención, sólo para matar el tiempo en lo que regresa Miguel. Así quedan diseminados en el texto una variedad de significados.

La estructura de la gran casa de la esquina también es representativa de la evolución social. Primero tenemos una casa muy organizada, pero luego comienza a degenerar el orden establecido por Trueba hasta convertirse en un laberinto de perspectivas.

24 David B. Dowing, "Deconstruction's Scruples: The Politics of Enlightened Critique," Diacritics 17-3 (1987): 71. 


\section{CONCLUSION}

En La casa de los espiritus definitivamente existe la "actitud reprobatoria contra todas formas de poder", que señala el crítico uruguayo Angel Rama al describir las escrituras de algunos novelistas hispanoamericanos actuales.

En su primera novela, Isabel Allende impugna los derechos de la clase dominante y quiere destruir la lógica social que los garantiza. Para lograr su propósito, trata de deconstruir la historia de su familia y de su país, desarticulando a la familia, la iglesia, el gobierno y otras instituciones sociales que tradicionalmente han sido elegidas como centro de la existencia. Allende desarticula estas instituciones mediante la presentacion de perspectivas variadas, que representan las ideas de una sociedad poscapitalista. Sin embargo, parece concluir que la sociedad pos-capitalista, con su diversidad de perspectivas no es la respuesta a un verdadero cambio social, ya que los diferentes puntos de vista, no sólo dividen a las masas, sino que tienen el efecto de disminuir una oposición de fuerza al poder económico dominante. A través de este estudio se ha podido constatar cómo Allende, con la destrucción de oposiciones binarias, demuestra que la diversidad de perspectivas mantienen a las mayorías en un punto medio, donde permanecen 
sin resolverse hacia una ideología en particular. Su opinión sobre las oposiciones binarias tradicionales queda expuesta en la novela durante el diálogo de Esteban Trueba con su hijo socialista, Jaime:

Usted es un perdedor sin remedio, hijo -suspiraba Trueba-. No tiene sentido de la realidad. Todavía no se ha dado cuenta de cómo es el mundo. Apuesta a valores utópicos que no existen. -No. La caridad, igual que su socialismo, es un invento de los débiles para doblegar y utilizar a los fuertes. -No creo en su teoría de los fuertes y los débiles-replicaba Jaime. -Siempre es así en la naturaleza. Vivimos en una jungla. -Sí, porque los que hacen las reglas son los que piensan como usted, pero no siempre será así. -Lo será, porque somos triunfadores. Sabemos desenvolvernos en el mundo y ejercer el poder. . (282)

La jungla es la confusión y las diferentes perspectivas que crean ese mundo donde hay que luchar para sobrevivir. El mundo utópico es aquel en que todos se pondrían de acuerdo para decidir por una forma de vida particular.

En el mundo actual no es fácil decidirse por una forma particular que sea la respuesta a la existencia de todos. La diferentes influencias politicas y sociales guiadas por el poder económico crean confusión y caos. No obstante, en 1970 los partidos izquierdistas chilenos logran, por medio del "laborioso proceso de educar al pueblo y de organizarlo" (316), terminar con la confusión. En este año se hacen aliados y ganan las elecciones. Pero el poder imperialista yanqui comienza su campaña de desestabilización económica que comienza nuevamente a crear divisiones y odios en el pueblo. A la nueva confusión y división de opiniones, añaden la 
fuerza de las armas. En el 1973, un golpe militar dirigido por Augusto Pinochet derroca el gobierno socialista de Salvador Allende. El ex presidente, tío de la escritora, es asesinado y una dictadura de derecha es establecida. Así se da fin a la trayectoria democrática que hasta entonces llevaba el país.

El poder económico pierde momentáneamente el control sobre el país, se les ha salido de las manos y con la violencia quieren asegurar que no pasará nuevamente. Así aseguran la circularidad de la historia de los países latinoamericanos. La escritora chilena está conciente de que un mundo donde no existan diferencias de opinión es una utopía y quizás por esta razón es que termina su texto con las misma palabras conque lo empieza, ya que no ve salida real al círculo vicioso en el que el poder económico la encierra. Por consiguiente parece opinar que, aunque no son perfectas, las formas más apropiadas para el desarrollo de la humanidad son aquellas que establecen formas políticas y economicas a base de la decisión de la mayoría, lo que constituye el sistema democrático. Así vemos sus comentarios acerca de los recientes sucesos que terminan con la dictadura es su país:

Creo que el gobierno lo está haciendo muy bien, con el respaldo de la gente. Lo cual es una sorpresa, porque chile es un país multipartidista, el que los chilenos se hayan puesto de acuerdo para un solo candidato, un solo programa, y para darle su apoyo a la democracia cristiana, que tiene muchos enemigos en la izquierda en Chile (porque se le culpa en parte 
del asesinato de Allende) ha sido como milagroso. 25

Además de deconstruir el contenido temático de su texto, Allende también destruye su estructura narrativa. Esto lo hace mediante el uso de técnicas narrativas como la multiplicidad de puntos de vista, la yuxtaposición de tiempo y espacio, la retrospección y la prolepsis, y el realismo mágico. El uso de técnicas como la multiplicidad de puntos de vista, ayudan a la escritora a crear un mundo en el que las realidades son infinitas e indefinibles. Con el elemento mágicorealista la autora logra enmascarar su actitud de denuncia, creando la ilusión de una evasión de realidades que puede 0 no existir.

Las técnicas narrativas antes mencionadas predominan la primera parte de la novela, creando un mundo fascinante para el lector. Luego de adentrase en el mundo fantástico de la gran casa de la esquina, es imposible salir sin saber los destinos de los personajes que allí viven, por lo que el lector continúa hasta el final. Ignorar la segunda parte, equivaldría a quedarse en el mundo mágico donde se puede evadir terribles realidades.

La casa de los espiritus refleja la vivencia de un pueblo que ha sufrido un tremendo "golpe" al perder, de manera violenta, la fe en las instituciones socio-políticas que lo representan. Un pueblo confuso que ha llegado a la

25 Isabel Allende, "Entrevista a Isabel Allende", Mester 20-2 (1991): 134 . 
conclusión de que la raíz del problema se encuentra en el dominio del poder económico, y en las oposiciones binarias que éste establece para mantener su control. 
BIBLIOGRAEIA

Abrams M.H. A Glossary of Literary Terms. Orlando: Dryden, 1985 .

Agosin, Marjorie. Women of Smoke: Latin American Women in Literature and Life. New Jersey: Read Sea, 1985.

Allende, Isabel. "La magia de las palabras." Revista Iberoamericana 132-133 (1985): 447-452.

Allende, Isabel. "Entrevista a Isabel Allende." Mester 20-2 (1991): 127-143.

Allende, Isabel. "Interview with Isabel Allende." Confluencia 6-1 (1990): 93-103.

Allende, Isabe1. Entrevista. "Los cuentes de Eva Luna: El nuevo libro de Isabel Allende." La Tortuga (Sin Fecha): $23-30$.

Allende, Isabe1. La casa de los espiritus. Barcelona: Rosés, 1982 .

Amaya, Lyana María. "La deconstrucción y la crítica feminista: Lecturas posibles de cien años de soledad Y Ia casa de les espiritus." Nuevo texto critico 1-2 (1989) : 189-195.

Antoni, Robert. "Parody or Piracy: The Relationship of The House of the spirits to one Hundred Years of Solitude." Latin American Literary Riview 32 (1988): 17-26.

Bautista, Gloria. "El realismo mágico en La casa de los espiritus." Discurso Literario 6-2 (1989): 299-310.

Boschetto, Sandra M. "Dialéctica matextual y sexual en La casa de los espiritus de Isabel Allende." Hispania 72$3(1989): 526-532$.

Cabrera, Vicente. "Modalidades textuales en La casa de los espiritus." Chasqui 20-22 (1991): 36-45. 
Canovas, Rodrigo. "Los espiritus literarios y políticos de Isabel Allende." Revista chilena de literatura 32 (1988): $119-129$.

Coddou, Marcelo. ed. Los libros tienen sus propies espíritus. Veracruz: Universidad Veracruzana, 1987.

Cortínez, Verónica. "La construcción del pasado en la historia verdadera de la conquista de la Nueva España y La casa de los espiritus." Hispanic Review 59-3 (1991): $317-327$.

Dowing, David B. "Deconstruction's Scruples: The Politics of Enlightened Critique." Diacritics 17-3 (1987): 66-80.

Eagleton, Terry. Literary Theory: An Introduction. Minneapolis: U. of Minnesota, 1983.

Earle, Peter G. "Iiterature as Survival: Allende's The House of the Spirits." Contemporary Literature 28-4 (1987): 543-554.

Epple, Juan Armando. "El estado actual de los estudio literarios en Chile: Acercamiento preliminar." Hispamérica 56-57 (1990):31-41.

Flores, Angel. "Magical Realism in Spanish American Fiction." Hispania (1955): 187-192.

Huerta, Teresa. "La ambivalencia de la violencia y el horror en La casa de les espíritus de Isabel Allende." Chasqui $19-1(1990): 56-63$.

Loach, Barbara Lee. "Power and Women's Writing in Chile: 1973-1988." DAI 51 (1991): 4138A. Ohio state U.

Meyer, Doris. "Parenting the Text: Female Creativity and Dialogic Relationships in Isabel Allende's La casa de los espiritus." Hispania 73-2 (1990): 360-365.

Muñoz, Willy o. "Las (re)escrituras de la casa de los espíritus." Discurse literario 5-2 (1988): 433-454.

Moody, Michael. "Isabel Allende and the Testimonianl Novel." confluencia $2-1(1986): 39-43$ 
Mora, Gabriela. "Las novelas de Isabel Allende y el papel de la mujer como ciudadana." Ideologies and Iiterature $2-1$ (1987): 52-61.

Promis, José. "Balance de la novela en Chile: 1973-1990." Hispamérica 55 (1990):15-23.

Rojas, Mario A. "La casa de los espiritus de Isabel Allende: Un caleidoscopio de espejos desordenados." Revista Iberoamericana 132-133 (1985): 917-925.

Suárez-Murias Margarite. et al. "El realismo mágico hispanoamericano: una definición étnica." Essays on Hispanic Literature. Washington, DC: University Press of America, 1982.

Thomson, Shields, E. "Ink, Blood, and Kisses: La casa de los espiritus the Myth of Disunity." Hispanefilia 99 (1990): 79-85. 